\title{
EL TRANSITO DE LA CRISIS DE 2007 A UNA POLITICA FISCAL COMÚN EN LA UE: LOS EUROBONOS Y EL PAPEL DEL BCE
}

\author{
The transition from the crisis of 2007 to a common eu fiscal \\ policy: eurobones and the role of the ECB
}

\author{
Fernando Martinez-Maillo Toribio \\ Doctor en Derecho \\ UNED
}

http://dx.doi.org/10.18543/ed-69(1)-2021pp127-153

Recibido: 15.03 .2021

Aceptado: 18.06 .2021

\section{Resumen}

La crisis de origen financiero iniciada en 2007, el inacabado proceso de construcción de la Unión Económica y Monetaria, así como las deficiencias del Eurosistema puso de manifiesto las debilidades de la Unión Europea. El BCE frente al resto de bancos centrales del mundo, tuvo sus propias limitaciones que condicionaron su respuesta.

El compromiso de los gobiernos para mantener unas finanzas públicas saneadas, con mecanismos de respuesta en caso de incumplimiento, unido a una política monetaria común orientada a la estabilidad de precios residenciada en el BCE, parecían suficientes ante la inexistencia de instituciones comunes presupuestarias. Este modelo quebró en momentos de crisis, apareciendo la necesidad de avanzar en el proceso de construcción de una Unión Fiscal real.

\section{Palabras Clave}

Banco Central Europeo, política fiscal común, eurobonos. 


\section{Abstract}

The origin of the financial crisis, that began in 2007, the unfinished process of building Economic and Monetary Union, as well as the shortcomings of the Eurosystem highlighted the weaknesses of the European Union. The ECB compared to the rest of the world's central banks, had its own limitations that conditioned its response.

The commitment of governments to maintain sound public finances, with non-compliance response mechanisms, coupled with a common monetary policy aimed at price stability based on the ECB, seemed sufficient in the absence of common budgetary institutions. This model that went bankrupt in times of crisis necessitated the need to move forward in the process of building a real tax union.

\section{Keywords}

European Central Bank, common fiscal policy, Eurobonds. 
Sumario: I. ANTECEDENTES: LA CRISIS ECONÓMICA DE 2007. II. EL BCE FRENTE A SUS PROPIOS LÍMITES. III. HACIA UNA POLÍTICA FISCAL COMÚN. IV. CONCLUSIONES. BiBliOgRAFIA.

\section{ANTECEDENTES: LA CRISIS ECONÓMICA DE 2007}

En este trabajo no se pretende hacer un estudio económico sobre la crisis económica iniciada en 2007, ni tampoco sobre las causas o sus evidentes consecuencias sobre la economía mundial y, en especial, sobre las economías europeas. Nuestro objetivo se limitará a tratar de analizar los mecanismos que en la actualidad tiene el BCE conforme a los Tratados para luchar contra ella, las deficiencias jurídicas de dichos instrumentos, y los pasos que se están dando o deben de darse para atajar de manera más eficaz futuras crisis similares.

Esta crisis iniciada en EEUU se convirtió en una crisis de la economía mundial, y en el caso de España, con características propias derivadas de la diversidad y particularidad de sus entidades financieras, así como de su excesiva exposición al sector inmobiliario, ha tenido unas duras consecuencias en términos económicos y sociales. Una crisis que no tiene precedentes en cuanto a la virulencia y capacidad de contagio: lo que inicialmente parecía ser un fenómeno local, ligado a las exposiciones ante las denominadas hipotecas subprime en Estados Unidos, se ha transformado en la primera gran crisis del siglo XXI.

Así se han expresado numerosos autores sobre las causas y las consecuencias de la crisis. El inicio fue un problema financiero y en concreto de liquidez, ya que al producirse el impago en las llamadas hipotecas subprime, los bancos que habían tenido que acudir a los mercados interbancarios, obteniendo financiación a corto, pero prestándolo a largo plazo, tenían un problema de liquidez al tener activos a largo y pasivos a plazo más reducido. «La evolución de esta crisis fue primero de liquidez, luego de solvencia y tras la caída de Lehman Brothers se transformó en una crisis de la economía real por falta de financiación para sus actividades» ${ }^{1}$.

El crecimiento económico previo a la crisis también generó buenos rendimientos en términos económicos en el marco del crecimiento y la creación de empleo, e incluso que el crecimiento económico fue un espejismo que llevó a las entidades financieras a infravalorar los riesgos que asumían en aras de no quedarse atrás en sus propios ratios de crecimiento: «La economía

${ }^{1}$ REINHART, C. y. ROGOFF, K.S: «Growth in a time of debit», National Bureau of Economic Research, January 2010. 
mundial disfrutó de un largo período de estabilidad, con significativos beneficios asociados, antes de que explotara la crisis financiera. Mientras duró, tuvo un crecimiento alto y estable, con baja inflación. Sin embargo, este período de estabilidad también favoreció el que los mercados financieros se lanzaran en una búsqueda frenética de rendimiento sin prestar la debida atención al manejo de los riesgos. Dichos períodos de estabilidad, en los que la tarea de la política monetaria era fácil, plantean un importante desafío a las autoridades, a los legisladores y al sector privado para monitorizar de cerca la formación de vulnerabilidades financieras» ${ }^{2}$

La Europa incompleta en lo económico también tuvo una especial incidencia en la respuesta ante la crisis. «El euro no deja de ser un tipo de cambio fijo...supone una especie de matrimonio múltiple entre diecisiete países, pero con separación de bienes» ${ }^{3}$, esta frase es perfectamente gráfica para explicar las deficiencias del sistema financiero europeo y su incidencia en la crisis.

Un euro a varias velocidades, con procesos de integración distintos, con países que forman parte de la zona euro de gran heterogeneidad, todo ello sin entrar en las claras diferencias económicas norte-sur que luego se trasladan a los propios instrumentos de decisión europeos, la cesión del tradicional instrumento de lucha contra cualquier crisis como es la política monetaria ya no es posible al estar cedida su competencia al Banco Central Europeo, y por último, la ausencia de una política económica única, tan solo coordinada en teoría pero no en la práctica, se ha impuesto como imposible de sostener si se pretende una estabilidad económica de la zona euro solo con la política monetaria, produciéndose choques entre países de un crecimiento y estructura económico distintos entre sí.

Muchas han sido las valoraciones que se han realizado tanto doctrinales como institucionales en torno a las medidas del BCE frente a la crisis, incluso a los grados de rapidez o celeridad en torno a dichas respuestas, pero con carácter previo a la concreción de éstas, me parece importante reflexionar sobre la posición del BCE en la crisis.

La importancia del papel que ha correspondido a la Unión Europea en la crisis está fuera de duda desde los albores de la crisis en 2007.

Uno de los principios y bases del proceso de creación europea siempre ha sido el del conocimiento y comprensión del fenómeno europeo en el conjunto de los ciudadanos, acercando las decisiones a éstos. Pues bien, con independencia de la comprensión de los ciudadanos en torno a las decisiones a adoptar, nadie puede dudar de que probablemente y como consecuencia de

${ }^{2}$ DE GREGORIO, J.: «El Rol de los Bancos Centrales tras la crisis financiera». Documentos de Política Económica del Banco Central de Chile, $\mathrm{n}^{\mathrm{0}} 36$, junio 2010.

3 DIEZ, J.L.: «Hay vida después de la crisis», ob.cit. 239. 
la crisis, el Banco Central Europeo sea una de las instituciones más conocidas, debatidas y observadas de la Unión Europea.

Esta crisis ha servido a la UE para ver las evidentes deficiencias de su sistema bancario en cada uno de los países, el gran contagio del sistema financiero, así como la ausencia de una rápida y única respuesta ante ello. Por todo ello, desde la UE se están dando los pasos necesarios para el establecimiento de la llamada Unión Bancaria, ya que su ausencia afecta directamente a los problemas de fragmentación y a los riesgos de ruptura que han distorsionado la transmisión de la política monetaria.

Así los bancos de la UE se encontrarán en igualdad de condiciones para la obtención de recursos de capital y financieros, estando sometidos a un único y soberano control, bajo los mismos mecanismos y criterios de solvencia, manteniendo como es lógico sus propios modelos de negocio siempre dentro de los criterios financieros que marcará el supervisor único dentro de la zona euro.

La propia diferencia de integración entre los países en relación con la política monetaria, en especial la ausencia del Reino Unido de la zona euro y pendiente en la actualidad de consumar su salida de la Unión Europea (Brexit), con su propio Banco Central con competencias en política monetaria aunque con coordinación de éstas a través del Sistema Europeo de Bancos Centrales, es otro elemento que incide en los mecanismos de resolución de la crisis económica, ya que todos los países y sus economías en el ámbito europeo están íntimamente relacionadas, cuando no a nivel incluso mundial como se ha visto en la actual crisis: «Se llega a la conclusión que las políticas monetarias del Banco Central y del Banco de Inglaterra se encuentran cointegradas, lo que indica la existencia de una relación de equilibrio a largo plazo entre ambas...Esto nos lleva a afirmar que el pertenecer a la Unión Económica y Monetaria conlleva más ventajas que inconvenientes ya que la política monetaria del Banco Central Europeo es la que influye en las políticas monetarias de la zona no euro, por eso algunos autores ${ }^{4}$ indican que el Reino Unido es vulnerable a una triple crisis financiera (crisis bancaria, monetaria y de deuda), debido a que es un país con gran exposición al sector bancario y que una moneda que no constituye una moneda de reserva global, y una capacidad fiscal limitada debido al gap de solvencia del sector bancario» ${ }^{5}$.

Otra opinión doctrinal avisa de ciertos riesgos inherentes al proceso de construcción de la Unión Económica y Monetaria: «El BCE es la única

${ }^{4}$ BUITER, W.: «Why the United Kindong should be join the eurozone», Intenacional Finance, 2011.

5 GONZÁLEZ VELASCO, M.C. y BRINCKMAN R.: «Análisis de la integración y dependencia de las políticas monetarias de la Unión Europea», Pecvnia Monográfico, 2011. 
institución europea que controla directamente un instrumento de política macroeconómica en la zona del euro, y existe el riesgo de que adquieran importancia las presiones para modificar su política, ejerciendo una influencia sesgada sobre la política monetaria del área, lo que haría del BCE una institución vulnerable, fácilmente perceptible por los mercados.... $\rangle^{6}$

Muchos son los retos que desafían el futuro de la Unión Económica y Monetaria y como consecuencia del Banco Central Europeo, que ha dejado precisamente al descubierto la coyuntura económica de crisis del momento: «La actual crisis financiera ha planteado retos importantes a la política monetaria de la zona del euro. En respuesta a la misma, el BCE, además de rebajar sus tipos de interés oficiales significativamente, ha adoptado una serie de medidas de política monetaria no convencionales que, colectivamente, se conocen como medidas de apoyo reforzado al crédito. Su introducción estuvo motivada por una necesidad de asegurar la continuidad de la efectividad de la transmisión de la orientación convencional de la política monetaria a unas condiciones financieras más amplias, a la economía real y, en última instancia, a la evolución de los precios, en un entorno en el que el sistema financiero estaba sometido a un estrés considerable. Por tanto, «las medidas no convencionales adoptadas por el BCE estaban dirigidas a complementar las decisiones estándar relativas a los tipos de interés, no a sustituirlas.. ${ }^{7}$

El BCE funcionó al principio de la crisis con medidas convencionales inyectando liquidez mediante operaciones de mercado abierto, «sin entrar en profundidad en un cambio de orientación de la política monetaria y composición de su balance» ${ }^{8}$, siendo su actuación además más tardía que otras como la FED, pero merece al menos el reconocimiento de haber sido rápido en responder con inyecciones masivas de liquidez, supliendo con ello la desaparición de mercado interbancario, convirtiéndose en el principal prestamista del mercado monetario, al existir una gran aversión al riesgo y un aumento exponencial de la desconfianza entre los intermediarios financieros.

«Durante esta crisis financiera el Banco Central Europeo redujo sus tipos de interés oficiales a niveles históricamente bajos y adoptó una seria de medidas de política monetaria no convencionales. Dichas medidas se han demostrado eficaces para restablecer, en gran parte, la estabilidad y la solidez del sistema financiero y de la economía, sin embargo, las perspec-

${ }^{6}$ CALVO HORNERO, A.: «La Unión Europea: Mecanismos financieros y moneda única», Ediciones Pirámide, Madrid 2010.

7 GONZALEZ-PARAMO, J. M.: «La gestión del Banco Central Europeo ante la crisis», Revista de Economía Mundial 30, 2012, pp. 83-102.

${ }^{8}$ AYUSO, J. y MALO DE MOLINA, J.L.: «El papel de los bancos centrales durante la crisis financiera; lecciones para el futuro», Papeles de la Fundación, $n^{\circ} 42$, Fundación de Estudios Financieros, Madrid, 2010, pp. 49-64. 
tivas a largo plazo de un crecimiento sostenible y de un sistema financiero estable en la zona euro requieren con urgencia la aplicación de diversas reformas de gran alcance a la arquitectura de la Unión Económica Monetaria y del sistema financiero» ${ }^{9}$

Cuando ocurrió la quiebra de Lehman Brothers en septiembre de 2008 se produjo el avance de los efectos de la crisis hacía la economía real, la del ciudadano concreto, lo que provocó la tímida pero firme decisión del BCE que adoptó distintas medidas no solo las convencionales que ya vimos, sino también medidas no convencionales, es decir, no utilizadas de manera habitual y cotidiana hasta ese momento para paliar y restablecer la confianza en los mercados y como consecuencia en la economía europea, en concreto en la zona euro, y en especial entre los países donde más se concretó la crisis entre ellos España.

Tras las hipotecas subprime en Estados Unidos, la crisis se desencadenó con una fugaz evaporación de la liquidez mundial, así como una abrupta reevaluación de los riesgos financieros con la quiebra de Lehman Brothers, la de Bear Sterns, el salvamento de AIG, la compra de Merril Lynch por Bank of América, etc., y más tarde la crisis financiera se transformó en una crisis de las economías reales en forma de una gran recesión y en una crisis de deuda soberana.

El BCE puso en marcha dos programas sucesivos de compras de bonos bancarios garantizados, cédulas o equivalentes, y otro de compras en firme de bonos públicos de países en tensión (SMP, Programa para los Mercados de Valores, por sus siglas en inglés), con la finalidad de restablecer la transmisión de la política monetaria.

Si esta acción del BCE la comparamos por ejemplo con la de otros bancos centrales como la Reserva Federal o el Banco de Inglaterra, la diferencia es clara, el menor peso relativo que ha tenido la compra de valores, sobre todo de deuda pública, frente el papel mucho más importante en tamaño y calidad, de las operaciones de préstamo a las entidades de crédito, lo cual tiene mucho que ver con las características estructurales de la UE, así como la singularidad de su composición en forma de Estados soberanos y con capacidad para tomar sus propias decisiones en materia económica.

\section{EL BCE FRENTE A SUS PROPIOS LÍMITES}

Dar una respuesta oportuna a la grave crisis económica internacional desde 2007 ha sido uno de los grandes restos de los Bancos Centrales en todo

${ }^{9}$ GONZALEZ-PÁRAMO, J.M.: «La crisis financiera mundial: Lecciones y retos» en P. Martín-Aceña (ed.), Pasado y Presente: de la Gran Depresión del siglo XX a la Gran Recesión del siglo XXI, Fundación BBVA, Madrid, 2012, pp. 167-208 
el mundo, al tener que afrontar problemas desconocidos basados sobre todo en el suministro de la liquidez y la estabilidad de los mercados a través de los que se transmite la política monetaria.

La crisis ha servido para reactivar el debate sobre el papel de la política monetaria para conseguir, además del objetivo irrenunciable de la estabilidad de los precios, el de la estabilidad financiera. «Si parece más fundamentada la necesidad de articular un nuevo ámbito de actuación de la política económica en torno al concepto de análisis macroprudencial con el objeto de identificar los riesgos para la estabilidad macrofinanciera y desarrollar la batería de instrumentos adecuada para prevenirlos o contrarrestarlos. Es una tarea en los que los bancos centrales por su situación privilegiada en el engranaje de los mercados financieros han de participar en cooperación con otras autoridades reguladoras y supervisoras, pero sin la pérdida de autonomía en el manejo de la política monetaria $\gg^{10}$

Otras cosas son las divergencias en el uso de las herramientas no convencionales entre los distintos bancos centrales en función de su estructura y objetivos concretos. Esa diferencia refleja una percepción, una valoración diferenciada, de los riesgos que podían ser asumidos por los distintos bancos centrales. La estrategia del Fed consistía en una mayor difuminación de los límites entre la política monetaria por un lado y las políticas fiscales y de estabilidad financiera por otro, lo que generaba indudables riesgos para la independencia de la autoridad monetaria que el BCE no asumió. Pero eso sí, la reacción de ambos bancos dejo claro la gran flexibilidad de las respuestas que tienen los bancos centrales en sus modelos actuales y su capacidad de invocación para adaptar sus decisiones a las coyunturas económicas del momento.

«Con el agravamiento de la crisis tras la quiebra de Lehman Brothers se hicieron necesarias acciones más contundentes que requirieron el recurso a medidas no convencionales de política monetaria a ambos lados del Atlántico, que respondieron a pautas más diferenciadas de acuerdo a sus respectivas características de sus sistemas financieros. $\rangle^{11}$.

La diferencia entre los distintos bancos centrales que existen en cualquier país desarrollado desde hace muchos años, son los objetivos concretos que guían su constitución, las funciones y objetivos que figuran en sus Estatutos. Lo que es evidente que un Banco Central no es cualquier banco, sino que es

10 AYUSO, J y MALO DE MOLINA, J. L.: «El papel de los bancos centrales durante la crisis financiera; lecciones para el futuro», Papeles de la Fundación, n 42 , Fundación de Estudios Financieros, Madrid, 2013.

${ }^{11}$ BCE: The Monetary Policy of the ECB. ECB. Third Edition, mayo 2011, y «El papel de los bancos centrales durante la crisis financier», 2013, Banco de España. 
un «banco de bancos», y para los Estados Unidos una agencia gubernamental que ocupa un lugar destacado en el sistema monetario y financiero del país, contribuyendo con ello al desarrollo de sistemas financieros y monetarios modernos dentro de una política económica definida por los gobiernos respectivos.

Desde la propia teoría económica y jurídica existen distintos modelos de banco central que han sido descritos por la doctrina: «Los trabajos de Rogoff (1985), Walsh (1995) y Svensson (1997) han planteado tres mecanismos alternativos que hacen posible la delegación de la política monetaria en bancos centrales independientes: a) el enfoque legislativo (Rogoff, 1985), consiste en elegir un banquero central que pondere de forma adecuada los objetivos de inflación y producción, dotándolo de autonomía por ley; b) el enfoque contractual (Walsh, 1995), propone el diseño de un contrato que penalice al banquero central de forma proporcional a la inflación; c) y el enfoque de objetivos, que se basa en que el gobierno fije un objetivo de inflación que ha de servir de referencia a las autoridades monetarias. El estudio comparativo de estos tres planteamientos ha constituido una referencia obligada en el debate sobre las reformas de las instituciones monetarias llevadas a cabo recientemente en un gran número de países, entre las que se destaca la creación del Banco Central Europeo...». ${ }^{12}$

Los objetivos esenciales de cualquier banco central son por un lado la estabilidad macroeconómica, fundamentalmente con el control de la inflación, e incluso el crecimiento estable de la economía como es el caso de la Fed no del Banco Central que no incluye este objetivo en sus estatutos fundacionales, creando con ello un marco de estabilidad macroeconómico que permita un crecimiento económico estable y duradero, sin grandes oscilaciones que pongan en peligro el propio objetivo del crecimiento.

Otras opiniones doctrinales afirman que: «Desde una perspectiva neokeynesiana, se explica que la política monetaria pueda llegar a ser temporalmente inconsistente cuando las autoridades pretenden actuar a la vez contra dos objetivos contrapuestos, como son el paro y la inflación, con una sola herramienta. El problema de la inconsistencia temporal afecta de forma determinante a la eficacia de la política monetaria. La solución que propone la literatura especializada es la cesión de las competencias de la política monetaria a un banco central independiente... Se considera que cuanto más independientes son los bancos centrales más creíbles son sus actuaciones contra la inflación, por lo que pueden reducir la inflación, con un coste social más bajo.... Por tanto, la transparencia y la consistencia de la política

${ }^{12}$ CAMPOY MIÑARRO, J. C. y NEGRETE MEDIAVILLA, J. C.: «Diseño de Bancos Centrales en economías abiertas: las ventajas del enfoque legislativo», Economía Internacional: Nuevas aportaciones, ICE $\mathrm{n}^{\circ}$. 814, marzo/abril, 2004 
monetaria en el tiempo contribuyen a mejorar la reputación de la autoridad monetaria, a fortalecer su credibilidad, sirviendo así de ancla de las expectativas de inflación de los agentes económicos» ${ }^{13}$

Para conseguirlo se utiliza fundamentalmente la política de los tipos de interés, bajándolos en los momentos de dificultad económica para incentivar la economía mediante el consumo o la inversión de las empresas y particulares por ejemplo en la construcción, y subiéndolos cuando se sospecha que la economía al crecer mucho está disparando la inflación, poniendo con ello en peligro el propio crecimiento de la economía. Estos mecanismos de subida y bajada de los tipos de interés se han utilizado desde siempre por todos los bancos centrales del mundo con mucha efectividad para controlar la inflación, y conseguir crecimientos económicos estables y duraderos.

No todos los bancos centrales tienen la función muy destacada como es la de mantener la estabilidad financiera, ya que ésta suele ir acompañada de la función de supervisión bancaria, de hecho, a pesar de que los Estatus del $\mathrm{BCE}$ contemplaban esta posibilidad no ha sido hasta ver las consecuencias de la crisis, y con un gran debate jurídico e institucional cuando el BCE ha asumido las competencias de supervisión financiera, y no de todas las entidades financieras.

Esta estabilidad financiera se consigue con un banco central fuerte, con capacidad de decisión enérgica y rápida, evitando los pánicos financieros que han sido una de las causas de quiebra del sistema financiero en otras épocas como en la Gran Depresión del 29 en Estados Unidos que provocaron la caída del sistema financiero, su confianza y una crisis económica de gravísimas consecuencias.

El medio que se utiliza fundamentalmente es la concesión de préstamos a corto plazo a las entidades financieras comerciales privadas para la consecución de liquidez que permita asegurar los depósitos bancarios y seguir concediendo créditos, evitando con ellos su quiebra y con ella la quiebra del propio sistema financiero de ese país y el eventual contagio al resto de países de su entorno o a nivel mundial al estar en todo, y más en lo económico, en un mundo globalizado.

Estos medios es lo que se denomina como el papel de los bancos centrales como «prestamistas de última instancia», cuando se cancela o disminuye sustancialmente los créditos interbancarios, o gozan de un interés inasumible, provocando que las entidades financieras carezcan de liquidez para mantener su actividad crediticia, y con ella garantizar los depósitos existentes en el banco, los bancos centrales actúan prestando dinero a corto plazo

${ }^{13}$ CASTAÑO M. S. y CARRASCO, I.: «Bancos Centrales, independencia, transparencia, credibilidad y el comportamiento de los agentes», Universidad de Castilla-La Mancha, Clm. Economía, $n^{\circ}$. 14, 2009, pp. 205-232. 
directamente a las entidades financieras privadas para dotarlas de liquidez, generando confianza y contribuyendo a la estabilización del sistema financiera y por lo tanto de la económica del país donde actúa el banco central.

Esta posición llevada al extremo prestamista de última instancia, como algunos llaman de «salvador de bancos privados» no deja de tener su contraparte crítica en los que opinan que genera un «problema de riesgo moral», porque genera incentivos para que las instituciones financieras adopten estrategias poco prudentes, basándose en que los distintos bancos centrales de cada país les salvarán. Esta situación debilitaría la propia disciplina del mercado y generaría una nacionalización de las pérdidas del sector privado que por otra parte recaerá sobre el contribuyente con su propio dinero, restándolo de otras finalidades u objetivos públicos y más necesarios.

También se critica no solo la cuestión moral de la ayuda a la salvación de los bancos privados por sí misma, sino incluso por su alcance, ya que se desconoce siempre cuando se adoptan este tipo de medidas cual es la dimensión de la «infección financiera», es decir, del «mal financiero», en el caso de la crisis financiera de 2007, la dimensión de las hipotecas basura, y por lo tanto, lo que significa que el valor de los bienes colaterales ofrecidos como garantía no deja de ser poco fiable, absorbiendo los distintos bancos centrales en sus balances activos cuyo valor de mercado resultaría inexistente o muy bajo con respecto a sus valores originales del mercado en que fueron concedidos, muy distintos al del mercado en la época de la ayuda.

Esto lleva a que algunas teorías sostengan que el mercado financiero debería sostenerse solo, cumpliendo la más pura ortodoxia bancario-monetaria, y en consecuencia purgar los excesos y errores cometidos durante el largo período de expansión crediticia. Con ello, se dejaría que quebraran o se reestructuren las instituciones financieras cuyo comportamiento le ha llevado a incurrir en riesgos excesivos e insostenibles en época de crisis.

Alguna doctrina financiera apunta en esa dirección: «El estallido de la burbuja inmobiliaria en Estados Unidos fue como un balde de agua fría sobre la economía mundial. Los mercados mundiales se volvieron volátiles y los flujos de capitales hicieron temblar a varias economías desarrolladas, desde países tan pequeños como Islandia hasta baluartes de la economía mundial como el Reino Unido..... La difícil situación atravesada por la economía estadounidense erosionó la confianza en la sustentabilidad del déficit de cuenta corriente estadounidense y, por extensión, socavó la confianza en el dólar, tal como había previsto Triffin hace más de medio siglo...» ${ }^{14}$.

${ }^{14}$ TRUCCO, P.: «¿Carga o privilegio? El dólar estadounidense y la puja por la reforma del sistema monetario internacional», Estudios Internacionales 169, Instituto de Estudios Internacionales, Universidad de Chile, 2011, pp-7-33. 
El debate sobre el rescate bancario sigue estando vigente en el debate político, institucional y doctrinal en Europa y por supuesto en todo el mundo desarrollado. Abandonar a su suerte a las entidades financieras en apuros no es planteada por ningún banco central serio en la actualidad, aunque existen distintos modelos para afrontar medidas concretas en contenido y en tiempo como se han visto ante la propia crisis financiera, pero ninguna de ellas la de dejar caer a las propias entidades financieras, ya que la experiencia de otras épocas especialmente la Gran Depresión de los años veinte del siglo pasado, donde esa teoría extremadamente ortodoxa en lo bancario, estuvo en la génesis de la gran crisis de esos años con las consecuencias ya conocidas, y el pánico generalizado con efecto contagio al resto de entidades financieras y al propio sistema financiero en su conjunto y a la propia económica nacional e internacional en concreto.

La Reserva Federal alimentó antes de esos años veinte del siglo pasado, primero una expansión de la oferta monetaria que condujo a una inflación de activos y después toleró una brutal contracción de esa variable que desencadenó el desplome del mecanismo de pagos de la economía norteamericana.

Por todo ello, la respuesta de todos los bancos centrales ante la crisis financiera ha estado muy alejada de ésta última teoría, obedeciendo a una clara lógica económica-financiera, interviniendo ante una clara amenaza de derrumbe del sistema de pagos, respondiendo con ello de manera razonable a la vista de la evidencia empírica y de la literatura económica disponible. «quizás si hubiese sido posible buscar alternativas en las cuales los bancos sólidos hubiesen creado un consorcio, o fórmulas similares, para sanear y consolidar a las entidades con dificultades. Por desgracia eso no ha sucedido, y no sabemos si el éxito habría acompañado los bienintencionados propósitos. Ahora ya es tarde para plantearse esa opción y lo único que se debe exigir al Banco de Inglaterra es que su intervención en el mercado sea prudente y, en todo caso, coyuntural. Esta no es la mejor alternativa, pero quizá es el mal menor» ${ }^{15}$

El propio Banco de Inglaterra en el año 2006-2007 adoptó y aprobó medidas contra la crisis financiera, en concreto aprobó un «esquema especial de liquidez» para conjurar el impacto sobre el sistema de pagos del Reino Unido de la crisis financiera, y así evitar que la restricción de liquidez y la fuerte corrección bajista del sector inmobiliario degenere en posiciones masivas de insolvencia en las instituciones de crédito, intentando con ello cumplir una de las tareas tradicionales de todo banco central, impedir la creación de un escenario de pánico en el cual el mercado no discrimine entre entidades que afrontan problemas de liquidez y otras que si lo tienen, incluso de solvencia.

15 Artículo «Virtudes y riesgos del mal menor: El Banco de Inglaterra ha acudido en socorro de las entidades financieras. Que dure poco, que sea coyuntural», Mervyn King gobernador del Banco de Inglaterra, Actualidad económica, abril-mayo de 2006. 
El Banco de Inglaterra con ello aplica la Ley Bagehot, suministrar sin límite el dinero que se demande por las instituciones financieras con tipos más altos como contrapartida, y con garantías sólidas para garantizar su devolución futura.

Los propios objetivos del BCE y su propia estructura jurídica e institucional limitan su capacidad de decisión: «La Fed considera de su responsabilidad no sólo el controlar la inflación sino también estimular el crecimiento económico, objetivo que no aparece en el mandato del BCE, cuyo objetivo principal es controlar la inflación, tiene una estructura descentralizada donde los representantes de los bancos centrales de cada país tienen un gran poder, sus decisiones son secretas y no tienen que explicar sus decisiones ni a las autoridades europeas ni a los Gobiernos de la UE. El Federal Reserve Board, por el contrario, es un organismo altamente centralizado, sensible a la opinión del Congreso de los EEUU, al cual tiene que rendir cuentas, siendo sus actas públicas» ${ }^{16}$.

Algunos autores apuntan a la propia estructura federal, la que motiva una distinta respuesta ante la crisis. "Si la Unión Europea tuviera un sistema federal como EEUU tendría más herramientas para solucionar los problemas económicos y financieros que están afectando a algunos de los países miembros, como consecuencia de la crisis. Si el Banco Central Europeo funcionara como la Reserva Federal de los Estados Unidos habría podido intervenir en la crisis de algunos Bancos para evitar que sean los Estados los que tengan que asumir la deuda privada de los Bancos en crisis. El problema de la UE, y muy particularmente de la Eurozona, es no tener una estructura federal como la que tiene EEUU. El problema de la Eurozona no es que Grecia o Irlanda tengan una deuda pública muy acentuada, sino que no existe una estructura federal y un Gobierno central que permita resolver el problema. El problema de la Eurozona no es un problema financiero, sino político, no existen las estructuras federales que permitan resolver los problemas que se den en esta unidad monetaria» ${ }^{17}$

Sin llegar a tanto, ni obligar a crear una estructura de Estado similar a la de EEUU como argumento para superar una crisis económica, es evidente que la Fed tiene más y mejores instrumentos, como se ha demostrado para dar respuestas sólidas y eficaces ante crisis económicas, como también veremos cuando realice las propuestas o conclusiones correspondientes. Pero lo cierto también es que la UE no es un Estado Federal y no parece que vaya en ese camino, ni siquiera es un Estado; es una organización internacional

16 VICENÇ NAVARRO: «¿Por qué la UE tiene un menor crecimiento económico que EEUU?», Temas para el debate, $n^{\circ}$ 125, 2005.

17 VICENÇ NAVARRO: «Si la Unión Europea tuviera un sistema federal como EEUU», Temas para el debate, $\mathrm{n}^{\circ}$ 197, 2011. 
compleja y diferente al resto donde hay una importante cesión de soberanía como en relación con la política económica; por eso, no se puede trasladar el modelo del Sistema Federal Bancario de EEUU automáticamente a la UE.

«En cuanto a los objetivos, la Fed siempre fue un organismo atento fundamentalmente a evitar presiones inflacionistas en la economía...Ahora bien, ante un panorama claramente recesivo, la Fed optó por tratar de incentivar el crédito y la demanda mediante una tasa de interés casi nula y con el apoyo a los planes de rescate financiero de grandes bancos y empresas comprometidas. Por cierto, cabe destacar que la Fed, empujada por la crítica situación, ha pasado a adoptar el papel, poco común para ella, de reactivador de la economía estadounidense, y ha dejado de asumir el clásico rol antiinflacionario». ${ }^{18}$

«Es evidente además que la política monetaria interactúa con la política económica en general, y en particular, con la política fiscal; mientras que la primera pasa a manos del $\mathrm{BCE}$, la segunda se queda en manos de los Gobiernos de los países que forman parte de la UE, lo que provoca evidentes tensiones y la son también evidentes la necesidad de que una y otra actúen coordinadamente. Basta decir que de nada serviría una política monetaria restrictiva si la fiscal fuese expansiva. Ni los Estados ni el Consejo ni el BCE pueden maximizar sus competencias hasta el extremo de desconocer la autonomía, las competencias y los intereses de los otros, lo que algunos autores han denominado «federalismo horizontal de los Estados $\rangle^{19}$.

«La independencia del BCE, y en general de la banca central, produce una suerte de federalismo de los poderes en el ámbito de la moneda. El banco es tan autónomo en su manejo como lo es, mutatis mutandi, una Comunidad Autónoma en el ejercicio de sus competencias. Esta federalización horizontal rompería los principios y esquemas tradicionales de ordenación-organización del poder ejecutivo y en general del Estado» ${ }^{20}$. «Se podría decir que estaríamos asistiendo a una fragmentación del poder del Estado; la quiebra del principio de jerarquía es la manifestación más elocuente $»^{21}$

${ }^{18}$ LICHTENSZTEJN TESZLER, S.: «Efectos observados y efectos inesperados de la crisis global», Iztapalapa Revista de Ciencias Sociales y Humanidades, $\mathrm{n}^{\circ}$. 70, enero/junio, 2011, pp. 39-50.

19 BETANCOR RODRÍGUEZ, A.: «La posición del Banco Central Europeo en el sistema institucional comunitario: independencia y equilibrio interinstitucional. El federalismo horizontal en el manejo de la moneda», Revista de estudios políticos, $\mathrm{n}^{\circ}$ 90, 1995 pp. 293-295.

${ }^{20}$ ALONSO GARCIA, R.: «Derecho Comunitario. Sistema constitucional y administrativo de la Comunidad Europea», CEURA, Madrid, 1994.

${ }^{21}$ PAREJO ALFONSO, L.: «Crisis y renovación en el Derecho Público», CEC, Madrid, 1991. 
«La Fed actuó más rápida y progresivamente que el BCE, aunque más tarde que los estadounidenses, los europeos se han tenido que emplear también a fondo» ${ }^{22}$. Esta es una descripción y para otros una crítica de la realidad de la actuación del Fed y del BCE en la crisis. Esta rapidez del Fed de actuación ante la crisis Charles Wypolz, profesor del Graduate Institute of Internacional Studies, piensa que el principal motivo fue «la cercanía», «al explotar la crisis en territorio estadounidense, con las tristemente conocidas hipotecas subprime, la Fed actuó desde el primer momento, en la zona euro no existían este tipo de productos de ahí el lógico retraso del $\mathrm{BCE}$ ».

En resumen, la propia estructura, competencias, funciones y origen histórico de los bancos centrales condicionan las respuestas ante situaciones de crisis económicas o financieras relevantes. No todos los bancos centrales del mundo son iguales, como tampoco lo son todos los Estados, como tampoco lo son todas crisis. Pero lo cierto es que cada crisis económica y/o crisis financiera nos deja algunas lecciones, y en el caso del BCE y en concreto de la UE, esta última ha motivado el avance hacia la Unión Bancaria, dotando incluso al BCE de funciones de supervisión financiera inéditas hasta el momento, e incluso derribando muros en la toma de decisiones no convencionales bajo la ya frase mítica y para la historia del entonces Presidente del BCE Mario Draghi «Haré todo lo que sea necesario, y créanme será suficiente».

La conclusión más evidente es que en el proceso de construcción de la UEM todavía quedan partes por cumplir, pero que el destino de ésta no puede quedar en manos de palabras más o menos mágicas que movilicen los mercados económicos o financieros, y si más bien en reformas de calado que garanticen al menos en términos de estructura institucional respuestas ágiles, creíbles y eficaces ante los nuevos desafíos que seguro que se irán presentando en el futuro.

\section{HACIA UNA «POLÍTICA FISCAL COMÚN»}

Paralelo a cualquier reforma de las estructuras institucionales y de las funciones del $\mathrm{BCE}$, debe ir acompañado en un avance claro en el proceso de creación de la Unión Económica y Monetaria, o lo que es lo mismo, debe de ir paralelo o unido a la creación en el seno de la zona euro de una política fiscal común.

El error ha estado y está en considerar que con la política monetaria sola, y vinculada exclusivamente con la estabilidad de los precios, se iba a atajar cualquier dificultad económica.

${ }^{22}$ Artículo de Rubén Nicolás, en Actualidad Económica, febrero 2010, «Duelo en las altas cumbres monetarias». 
La crisis iniciada en 2007 ha puesto de manifiesto por un lado las debilidades de supervisión bancaria en la zona euro que se pretende conseguir con los avances hacía una supervisión única por parte del BCE, y por otro la diversidad de la Eurozona con países que accedieron al euro con estructuras económicas muy diferentes y con políticas fiscales y presupuestarias poco coherentes, y por lo tanto con un proceso de construcción en lo económico y monetario en el seno de la UE claramente incompleto. Tenemos un mercado común y una moneda común, pero sin políticas fiscales comunes.

$\mathrm{Si}$ a eso le sumamos un banco central sin todos los instrumentos necesarios para luchar contra la crisis, y con unos objetivos muy estrictos vinculados en exclusiva con la estabilidad de precios, nos da una radiografía precisa de la situación actual, y también de los necesarios cambios que se pueden plantear en el futuro.

Estamos ante lo que se ha denominado como una «Europa incompleta», que ha tenido evidentes consecuencias en la respuesta ante la crisis. Y como diría J.L. Díez: «La eurozona no deja de ser un matrimonio múltiple entre diversos países, pero con separación de bienes», ${ }^{23}$ descripción que pone de manifiesto las carencias en el proceso de construcción europea hacia una verdadera Unión Económica y Monetaria, y la necesidad por tanto de introducir modificaciones y cambios, que nos permita avanzar continuando con el símil, hacia un matrimonio entre varios países, pero en régimen de gananciales.

La estabilidad económica de la zona euro se ha demostrado que no es solo posible con la política monetaria; la ausencia de una política económica única, tan solo coordinada como se establecen en los tratados, ha demostrado que ha generado choques entre lo económico y lo monetario, y entre gobiernos de distintos países de crecimiento y estructuras económicas distintas entre sí.

En estos momentos se hace necesario de forma inevitable si se pretende seguir avanzando en un proceso de construcción europea sólido y que garantice una estabilidad económica en la zona euro de cara al futuro, una nueva transferencia de soberanía a las instituciones europeas para compensar los desequilibrios estructurales en la zona euro, o bien hacia una coordinación reforzada de las políticas económicas de los Estados miembros, o bien hacia una unión fiscal y presupuestaria real.

La política fiscal no es otra cosa que la cantidad y el modo en que los gobiernos recaudan y gastan, es decir, de qué modo administran sus presupuestos, y en la actualidad dichas políticas son responsabilidad de los Estados, aunque los veintisiete deben coordinar sus políticas fiscales de acuerdo con las directrices marcadas por el Pacto de Estabilidad y Crecimiento y por

${ }^{23}$ DÍEZ CANGAS, J.C., Hay vida después de la crisis, Plaza y Janes, Barcelona 2013. 
el Tratado que limitan el gasto y el endeudamiento de los gobiernos. La simple coordinación de la economía, de la política fiscal y presupuestaria que establecen los Tratados se ha demostrado insuficiente, así como escasamente exigente como se ha demostrado en los casos de incumplimiento del Pacto de Estabilidad y Crecimiento.

El compromiso de los gobiernos para mantener las finanzas públicas saneadas, y los mecanismos de respuesta por su incumplimiento, parecían suficientes ante la ausencia de instituciones federales de tipo financiero y presupuestario, y unido a una política monetaria común orientada a la estabilidad de precios, se pensaba suficiente para garantizar un alto nivel de crecimiento económico y altos niveles de empleo, y las cosas funcionaron mientras la economía creció, pero ante las dificultades, y especialmente con la crisis financiera a partir de 2007, se ha demostrado que todas esas reflexiones y argumentos han sido superadas por la realidad actual.

El planteamiento por tanto consistiría en que no existen alternativas a «más Europa», que la simple coordinación económica no ha servido ha sido deficiente, y que incluso los países de economías más potentes con Alemania a la cabeza nunca aceptará la asunción entre todos los países la responsabilidad de la deuda pública común, emitiendo bonos europeos, mientras no exista una rápida y profunda armonización fiscal en los impuestos, en los límites de gasto y el déficit público final, lo que implicaría una reforma de los Tratados, que sin duda no es rápida al llevar aparejado una nueva transferencia de soberanía y por lo tanto la ratificación por cada uno de los Estados, con los consiguientes riesgos de negativa como ya sucedió, pero dichos riesgos no son ni pueden ser impedimento para avanzar en dicho proceso, dejando atrás un modelo ambicioso basado en una política monetaria centralizada y única con políticas económicas descentralizada pero coordinada, que a la vista de todo lo que ha sucedido en especial como consecuencia de la crisis se ha demostrado insuficiente y lleno de ineficiencias.

La última crisis ha demostrado la tremenda interacción, por no decir interconexión, entre política monetaria en manos del BCE, política fiscal en manos de los gobiernos nacionales y la estabilidad financiera, generándose un peligroso triángulo de potenciales peligros económicos, donde solo la solución a uno de ellos se ha demostrado que no es suficiente. Hay que liberar a la política monetaria de tener que dar respuestas a elementos negativos derivados de otras áreas de la política económica.

El avance hacia la Unión Bancaria con una supervisión bancaria única en manos del BCE es un paso en la buena dirección, pero se han demostrado evidentemente poco exitosas las fórmulas de mejora de un marco de gobernanza económica, para conseguir una mayor disciplina fiscal y una mejora de la competitividad de la zona euro. Entre otras cosas porque el éxito de ese marco de gobernanza económica de los países de la zona euro, depende en 
buena medida de la velocidad y alcance de su ejercicio y desarrollo, dejándolo en todo caso en manos de la voluntad de los Gobiernos nacionales, y eso ya se ha demostrado que resulta insuficiente.

Baste recordar la deficiente aplicación del Pacto de Estabilidad y Crecimiento que pretendía mantener las condiciones de convergencia nominal de los países de la UE, en especial de la zona euro, y lograr con ello la estabilidad del euro como condición necesaria para la incorporación a la moneda única, con los incumplimientos de importantes países con procesos de déficit excesivo que finalmente quedaron en escasas por no decir nulas consecuencias.

Existe en el seno de la UE un amplio consenso en torno a que las finanzas públicas saneadas son esenciales para el crecimiento y la estabilidad económica, estableciéndose reglas concretas sobre el comportamiento fiscal de los Gobiernos de los Estados miembros concretados en el Pacto de Estabilidad y Crecimiento con sus distintas versiones que se han realizado a lo largo de los años, que como ya hemos visto han sido insuficientes. Existía en el seno de la UE la consideración de que la política fiscal estaba situada en un nivel de consideración inferior al de la política monetaria al que se le prestó toda la atención, y se ha demostrado una estrategia equivocada.

En 2011 en plena crisis económica se avanzó en subsanar las deficiencias del marco institucional de la Unión Económica y Monetaria adoptándose una seria de iniciativas o medidas relativas a la política fiscal y macroeconómicas, que pretenden mejorar las reglas fiscales de la UEM y contribuir a restablecer la disciplina fiscal para un buen funcionamiento de la UEM, reforzando con ello la dimensión económica de ésta y con ello una mayor integración económica en la zona del euro. Con las reformas del marco de gobernanza económica se pretende un primer y necesario paso en la idea de reforzar los cimientos económicos en la UE, y en especial en la zona euro, haciendo recaer en su aplicación y cumplimiento riguroso una vez más, el éxito de dichas medidas ${ }^{24}$.

En definitiva, en la actualidad la coordinación de la política económica o los marcos de gobernanza económica de la UE siguen en manos de la

${ }^{24}$ Sobre el papel del BCE en la gobernanza económica de la UE, que ha dado lugar a la emergencia de una «proto-constitución» económica o un Derecho constitucional económico, puede verse TUORI, K./ TUORI, K., The Eurozone Crisis. A constitutional Analysis, CUP, Cambridge, 2014. En España, GORDILLO PÉREZ, L.I. y CANEDO, J.R., «La Constitución económica de la Unión Europea. Bases de un modelo en constante evolución», en Cuadernos de Derecho Transnacional (marzo 2013), Vol. 5, No 1, pp. 163-183. Asimismo, GORDILLO PÉREZ, L.I., «Constitución económica, ordoliberalismo y Unión Europea. Ensayo de una caracterización del Derecho económico europeo», en GARCÍA GUERRERO, J. L. (Dir.), Constitucionalizando la globalización, Tirant, Valencia, 2018, pp. 813-845. 
voluntad política de los Gobiernos de los países miembros de la zona euro, eso sí con un refuerzo de las exigencias e incluso de las posibles consecuencias en caso de incumplimiento. Pero todas esas medidas se han demostrado insuficientes, ya que su incumplimiento o deficiente cumplimiento, dependen como hemos dicho de la iniciativa y autoexigencia de cada uno de los Estados miembros. Es más, dichas políticas fiscales exigentes acordadas en las instituciones de la UE, la crisis ha demostrado que su cumplimiento o incumplimiento afectan también a la política monetaria, en una suerte de vasos comunicantes, que es necesario taponar con reformas estructurales importantes en el seno de la UE, donde se proceda a una nueva cesión importante de soberanía con el escenario a medio plazo de la Unión Fiscal.

Se trataría de avanzar hacia un gobierno económico en el seno de la Unión Europea que fije una auténtica dirección en la política fiscal y económica, para lo que es necesario dotarlo de competencias reales, por lo que la modificación de los Tratados se antoja absolutamente necesaria como veremos en el último punto de estas propuestas.

Esa gobernanza común económica en la Eurozona como espacio no ya de coordinación económica sino de consecución de una política económica y fiscal común, con una institución europea de referencia que la posibilite, y con la creación de un instrumento de deuda pública europea conocidos como eurobonos. Estos conducirían a reforzar la estabilidad financiera en la zona euro, ya que una buena parte de la deuda pública de los países de la eurozona está en la cartera financiera de las entidades financieras de dichos países, lo que ocasionó la transmisión rápida de los problemas entre sector público y privado.

La creación de un Tesoro Público a nivel europeo nos situaría en una posición cercana que no equiparable al bono del Tesoro de los Estados Unidos que los mercados conocen y saben que es un activo seguro pese a las dificultades pudiera haber eventualmente en las finanzas federales de dicho país. Sin embargo, en la Eurozona se podría quebrar el «riesgo-país» con la creación a medio o largo plazo de los eurobonos, siendo plenamente consciente que este proceso solo se consumará si existe previamente una unión fiscal ya que al emitirse deuda pública el riesgo sería compartido por los países de la zona euro con los riesgos que ello generaría sin una unión económica y presupuestaría previa.

La emisión debería realizarla una institución europea de la eurozona, de carácter por tanto supranacional, con un mecanismo de emisión conjunto cuyo primer efecto debería ser la reducción de los intereses que pagan los países por la emisión de su deuda pública, y con ello se resolverían problemas de liquidez que en la actualidad tienen o han tenido algunos países como España o Italia durante la crisis, al tener que pagar intereses mucho más altos que los de la deuda del resto de países de la Eurozona, resolviéndose las crisis de deuda sin necesidad de acudir a estímulos no convencionales como los 
surgidos durante de la crisis y que tuvo que aplicar el BCE para mantener la estabilidad del euro. A esto habría que añadir que, al estar la deuda homogeneizada, se estaría avanzando decididamente en el proceso de integración económica en la Eurozona,

Estamos hablando de un objetivo que en estos momentos se alcanza a medio y largo plazo, y que solo cabría plantearse en estos términos si previamente se ha avanzado en la construcción de la Unión Económica y Monetaria ahora incompleta, con la creación de un ente europeo al que le puedan ser transferidas algunas competencias de política económica, una especie de Ministerio de Economía Europeo para los países de la zona euro, que sirva para mejorar los mecanismos que guían la política fiscal de las economías de la zona euro, pasando de la simple coordinación a la unificación de las mismas, al menos reforzando las reglas europeas que deben cumplir los distintos países de la eurozona.

En ese momento, la creación del Tesoro Público que ya la Comisión ha planteado a nivel europeo como una opción, cobraría toda su vigencia. Un Ministerio de Economía Europeo, que habría que definir sus competencias, y también su financiación vía transferencia parcial o total de algún impuesto nacional o transferencias ordinarias de los Estados o bien acudiendo al mecanismo de deuda pública a través de los Eurobonos, que en este contexto de avance hacia la Unión Fiscal cobraría todo su significado. Pretender alcanzar el objetivo de un Tesoro Público Europeo sin previamente la consecución de una Unión Fiscal, manteniendo las competencias presupuestarias en manos nacional, se alcanza como utópico, por las reticencias de los países menos endeudados que ven en la mutualización de la deuda un riesgo para sus economías.

Ni siquiera algunas opciones acuñadas por la Comisión como los «eurobonos sintéticos» (SBBS en sus siglas en inglés, «Sovereign bond-backed securities») que no son más que valores respaldados por bonos soberanos que no requiere que los países agrupen los préstamos, han alcanzado la luz por la reticencia de los mismos países de siempre, que mantienen su posición en torno al principio de la propia responsabilidad de los Estados miembros en su política económica y presupuestaria, y por temor a que este mecanismo de nueva creación acabe apoyando a los países más endeudados por la puerta de atrás, adquiriendo de nuevo dinero más barato y aumentando más el gasto público bajo el paraguas europeo. Este nuevo mecanismo busca diversificar las exposiciones de la deuda soberana, ya que en los bancos hay mucha deuda pública al ser las entidades financieras las principales compradoras de dicha deuda, pero que cuando llegan las crisis los problemas se multiplican, al existir un gran vínculo entre entidades financieras y país, buscando este nuevo instrumento de ingeniería financiera debilitar dicho vinculo financiero-soberano.

Sin avances en Unión Fiscal no cabe hablar de Eurobonos, ésta en la principal conclusión, y el principal reto al que se enfrenta el futuro de la Eurozona, junto con la culminación de la Unión Bancaria. 


\section{IV.CONCLUSIONES}

La trascendencia del Banco Central Europeo cobra una extraordinaria importancia a la luz de la crisis económica que comenzó en el 2007. Hasta ese momento para buena parte de la opinión pública el BCE era una institución más de la UE unida al nacimiento del «euro» y a la transferencia de soberanía de los Estados de la Eurozona, pero no se había llegado a discutir tan ampliamente sobre sus funciones, el alcance de sus competencias, las razones de los cambios legislativos que eran necesarios, si dichas funciones condicionaban o no las respuestas ante la crisis financiera y económica que se estaba viviendo, e incluso la comparativa con el resto de bancos centrales del mundo especialmente la Fed.

Pues bien, a partir de la última crisis económica, el BCE se ha encumbrado como una de las instituciones más relevantes de la UE, la institución que más competencias ha asumido desde entonces, la que más ha dado objeto a discusiones económicas y políticas en torno a sus decisiones para hacer frente a la crisis financiera, e incluso protagonizar y ser el centro de las futuras reformas en el seno de la Unión Europea.

Las características intrínsecas al devenir de la UE prácticamente desde su origen hay que verlas como un elemento positivo y de oportunidades de cara al futuro, pero debemos de resaltar también sus riesgos, traducidos en la complejidad en la toma de decisiones, la propia existencia de varias velocidades en función de los intereses de cada país debilita de alguna manera el proyecto europeo, o la lejanía de los ciudadanos en la propia toma de las decisiones cuando estas son protagonizadas por órganos europeos cuya organización y estructura han sido objeto de críticas por falta de transparencia, cuando no de déficits democráticos como luego analizaremos. En todo caso, pese a estos inconvenientes, el proceso de construcción de la UE y en concreto el proyecto hacia la UEM representa en sí mismo avances que debemos resaltar y valorar positivamente.

Las grandes decisiones de la Unión Europea en torno a una mayor integración se van adoptando con una aparente desesperante lentitud; poner de acuerdo a países distintos, con estructuras políticas y económicas diferentes, en momentos no coincidentes bajo el criterio de oportunidad no es tarea fácil; cualquier proceso de esta naturaleza exige cesión de soberanía y el impacto de ello en la opinión pública de los diferentes Estados es siempre un tema sensible. Mediante la creación del proceso por etapas, no solo facilita dicho entendimiento, sino que permite la conclusión de los procesos jurídicos, políticos e incluso económicos necesarios para la consecución del objetivo.

Es cierto que la política monetaria ha estado presente desde el inicio del proceso de construcción europea, pero no es menos cierto, que su desenvolvimiento ha sido siempre convulso. 
A partir del Tratado de Maastricht, donde se introduce en el marco de las competencias la creación de la Unión Económica y Monetaria, se ha traspasado la puerta hacia la integración política pero lentamente, aunque esa no fuera la idea inicial de sus «padres políticos», para lo cual ha sido necesario ir cediendo ámbitos de acción que pertenecen a la soberanía de un país.

La puesta en circulación del euro, en la tercera fase del proceso de la unión monetaria, constituyó uno de los hitos más relevantes de la construcción europea, superando incluso las previsiones de los escépticos y de parte del mundo económico y político que dudaban de la posibilidad de una unión monetaria entre países de un mismo continente, pero tan distintos, por no decir dispares, pronosticando su fracaso.

El euro es, sin duda, la historia de un éxito en términos políticos y, sobre todo, económicos, que ha traído bienestar a una parte importante de la ciudadanía europea, pero, como en todo proceso y, la construcción europea no es una excepción, ha presentado dificultades. La complejidad del proceso de integración europea justifica plenamente estos problemas, pero no que sean utilizados por algunos para demorar o, incluso, detener el proceso de construcción europea que, como se ha dicho reiteradamente, parece siempre inacabado.

Es evidente que la creación de una moneda común supuso la cesión de competencias de los Estados miembros que así lo hicieron, es decir, una cesión de soberanía monetaria compleja, que supuso la creación de una estructura institucional que sirviera a los objetivos de la única dirección de la política monetaria, pero que conservaba para su ejecución los Bancos Centrales Nacionales, por lo que se constituyó no sólo una institución nueva el Banco Central Europeo, sino un Sistema, es decir, un instrumento, sin personalidad jurídica, que coordine la ejecución de la política monetaria en la zona euro.

Para los países que todavía no han adoptado el euro, y por lo tanto conservan intacta su soberanía en las competencias monetarias, con sus propios bancos centrales nacionales ejerciéndolas, se adoptó la decisión de que pertenecieran al SEBC, aunque sin personalidad jurídica y sin funciones ejecutivas concretas, parece más un instrumento de transición para solucionar la aparente contradicción de la existencia en el seno de la UE de países con moneda única y países alejados de este modelo. Se pretende con ello dar una coherencia mínima a la política monetaria de la zona entre los Estados miembros de la UE, con independencia de si han adoptado o no el euro. El SEBC seguirán coexistiendo mientras continúe habiendo Estados miembros de la UE que no pertenezcan al euro, pese a carecer de personalidad jurídica, formando una «entidad virtual», sin órganos rectores propios correspondiendo éstos últimos a los del BCE.

El modelo de la Unión Económica y Monetaria que se gestó en Maastricht es evidente que ha funcionado cuando las circunstancias económicas han 
sido favorables, pero también es evidente que la crisis ha sacado a la luz algunas de sus importantes debilidades, que en algunos casos ya se vieron como amenazas con mucha anticipación, cuya ausencia de subsanación ha provocado que la respuesta de la UE, y especialmente de la Eurozona, a las turbulencias de la crisis hayan sido más tardías y más débiles que el resto de las zonas económicas también afectadas por la crisis, y en concreto de la Fed o del Banco de Inglaterra.

Hay tres elementos que configuran a mi juicio la necesidad de un cambio de modelo institucional en las instituciones europeas, especialmente vinculadas con la Unión Económica y Monetaria, y en concreto del BCE: La implantación de una política monetaria por parte del BCE para países de la zona euro con características económicas no solo distintas sino en algunos casos contrapuestas; el incumplimiento del Pacto de Estabilidad y Crecimiento por importantes países como Alemania y Francia, generando una especie de «amnistía a la carta» en función de la importancia del país incumplidor, provocando además una relajación de las normas aplicables al caso, que restó credibilidad al contenido y objetivo de dicho Pacto; la profunda debilidad de la llamada coordinación de las políticas económicas de los países de la zona euro, que estaba construida solo con la propia base de las intencionalidades o voluntades políticas del gobierno del país concreto de que se trate; y por último, la ausencia de una verdadera y única supervisión bancaria de la zona euro, haciendo además descansar, como consecuencia de la inexistencia de una Unión Bancaria, en los países la respuesta a las consecuencias de las quiebras bancarias, existiendo además una evidente transmisión entre riesgo bancario y riesgo país y/o viceversa.

Todo ello, sumado con otras concausas, hace necesario avanzar decididamente en la reforma de la estructura institucional de la Unión Europea, especialmente de aquellas instituciones como el BCE que tienen la competencia directa en la política monetaria de los países de la zona euro, por cuanto se ha demostrado que la respuesta del BCE a la crisis ha sido diferente, en tiempo y en algunos contenidos, a la realizada por la Reserva Federal de los Estados Unidos o por el Banco de Inglaterra, sino que los medios de los que disponía el BCE para ello, es decir, su estructura institucional, sus objetivos estatutarios, su sistema de decisión etc. han contribuido a limitar sus respuestas.

Esta reforma exige cambios en el gobierno económico de la zona euro, pasando de un modelo de coordinación fundamentalmente dual a través del Eurogrupo y del Comisario de Economía, hacia un modelo integrado en lo fiscal y presupuestario, ante los evidentes fracasos del Pacto de Estabilidad y Crecimiento acaecidos en su reciente historia, avanzando por último y como consecuencia de lo anterior en la mutualización de la deuda pública, creando un Tesoro Público Europeo, con una institución propia y dando luz por fases, tramos o como se quiera concretar, la figura ahora impensable sin gobierno 
económico pero posible con él, de los «eurobonos» eliminando la disparidad del coste de financiación de la deuda entre países, y evitando que futuras crisis financieras acaben en crisis económicas en la zona euro.

Es cierto que, tras el fracaso del Tratado Constitucional, el Tratado de Lisboa supuso un avance importante en el proceso de construcción de la UEM. La sola consideración del BCE como una institución más de la UE, incluyéndola por primera vez en el apartado de «Instituciones Europeas» (Título III), mientras que con anterioridad estaba bajo el epígrafe de «Otras instituciones», ha sido uno de los avances más importantes antes de la crisis. Aunque parezca un cambio puramente léxico o semántico, no lo es, por cuanto por primera vez se reconoce al BCE como una institución de la UE como las demás, y por lo tanto obligada a cumplir los objetivos de la Unión.

Pero después de la última crisis, donde se han visto más las debilidades del proceso incompleto hacia la UEM, exige de reformas más profundas, que complementen y avancen hacía las ya realizadas a partir de 2012 como por ejemplo en la Unión Bancaria, con la atribución como dato más destacado de la supervisión bancaria al BCE entre otras decisiones que se adoptaron.

Se trata de incorporar las reformas institucionales y legales que avancen hacía la culminación de la UEM, con contribuyan al fortalecimiento del «euro», que contribuyan a que las instituciones monetarias europeas tengan los mecanismos jurídicos y económicos necesarios a su alcance para abordar cualquier situación de crisis, eliminando las dudas que han existido sobre la idoneidad, alcance y fines de los objetivos estatutarios del BCE, y así evitar las dudas que ha generado la intervención del BCE en la última crisis que ha recibido importantes reproches doctrinales y de opinión pública en torno a su actuación tardía, cuando no errática, su «obsesión» de la institución por el control de la inflación relegando al olvido otros objetivos como el crecimiento económico, e incluso su actuación en algunos casos a remolque de las decisiones de otros Bancos Centrales.

\section{BIBLIOGRAFIA}

Alonso Garcia, R: «Derecho Comunitario. Sistema constitucional y administrativo de la Comunidad Europea», CEURA, Madrid, 1994.

Álvarez Martinez, J. y Salinas Alcega, S.: «La aplicación del procedimiento de déficit excesivo: los casos de Francia y Alemania». Análisis de la Sentencia del Tribunal de Justicia de las Comunidades Europeas de 13 de julio de 2004 (asunto C-27/04, Comisión contra Consejo), Instituto de Estudios Fiscales, 2005.

Arenas Rosales, R.: "Crisis financiera estadounidense: ¿al límite del abismo?», Espacios Públicos, Vol. 12, nº. 24, Universidad Autónoma del Estado de México, México, abril 2009. 
Ayuso, J. y Malo De Molina, J.L.: «El papel de los bancos centrales durante la crisis financiera; lecciones para el futuro», Papeles de la Fundación, nº. 42, Fundación de Estudios Financieros, Madrid, 2013.

Benzo, A.: «Construir una Unión Bancaria», Papeles de Economía Española, $n^{o}$. 137. 2013. https://www.funcas.es/publicaciones/Sumario.aspx?IdRef=1-01137

Betancor Rodríguez, A.: La posición del Banco Central Europeo en el sistema institucional comunitario: independencia y equilibrio interinstitucional. El federalismo horizontal en el manejo de la moneda». Revista de estudios políticos, $\mathrm{N}^{\mathrm{o}}$ 90, 1995.

BUITER, W: «Why the United Kindong should be join the eurozone», International Finance, 2011.

Calvo González, J. L. y Calvo González, T.: «El Banco Central Europeo ante la crisis ¿Otra política habría sido posible?», Revista Universitaria Europea $\mathrm{n}^{\circ} .19$, diciembre 2013.

CAlvo Hornero, A.: La Unión Europea: Mecanismos financieros y moneda única, Ediciones Pirámide, Madrid 2000.

Campoy Miñarro, J. C. y Negrete Mediavilla, J. C.: «Diseño de Bancos Centrales en economías abiertas: las ventajas del enfoque legislativo», Economía Internacional: Nuevas Aportaciones, ICE, nº 814, marzo-abril 2004.

Castaño Martínez, M. S. y Carrasco Monteagudo, I (2009): «Bancos Centrales, independencia, transparencia, credibilidad y el comportamiento de los agentes», en Clm.economía, núm. 14, 2009.

De Gregorio, J.: «El Rol de los Bancos Centrales tras la Crisis Financiera», Documentos de Política Económica del Banco Central de Chile, no . 36, junio 2010.

De LA Dehesa Romero, G. «¿Cómo nació el euro?», Libros de economía y empresa, $n^{\circ} 1,2010$.

Díez Velasco, M.: Las Organizaciones Internacionales, Tecnos, 14 edición, Madrid, 2006.

Díez Cangas, J.C., Hay vida después de la crisis, Plaza y Janés, Barcelona 2013.

FARHI, M. y MACEDO CINTRA, M. A. «Crisis financiera internacional: contagio y respuestas regulatorias», Revista Nueva Sociedad n 224, noviembre/diciembre, 2009.

FERnÁndez MÉndez De Andrés, F.: «El Banco Central Europeo y los límites de la política monetaria». ICE una Política Económica para la Recuperación, ${ }^{\circ}$ 883, marzo-abril 2015.

Galindo Martin, M. A., Montero Lorenzo, J.M. e Iglesias SuÁrez, A.: «Déficit Público y Pacto de Estabilidad y Crecimiento: el reto de las economías europeas», Universidad de Castilla-La Mancha, Economía, nº 1 , segundo semestre de 2002.

Garcia Iglesias, J.M. y Pateiro Rodriguez, C.: «Análisis de la estrategia de política monetaria del Banco Central Europeo (1999-2005)», Trimestre Económico, 2009.

Garcia-Legaz, J.: «La reforma del Pacto de Estabilidad y Crecimiento: un error histórico», Cuadernos de Pensamiento Político, Enero/Marzo 2005.

Gonzalez Botisa, F.: «Los límites de la autonomía del BCE», comentarios a la Sentencia del Tribunal de Justicia de 10 Julio de 2003. Revista española de derecho administrativo, $\mathrm{n}^{\circ} 123,2004$ 
Gonzalez Iban, R.: «Política Fiscal del Euro y el Pacto de Estabilidad y Crecimiento», Políticas Económicas del Euro, n 784 marzo-abril 2000.

GonZAlez- PÁrAmo, J.M. «Retos de la nueva Europea: La culminación de la Unión Económica y Monetaria», Conferencia Club Siglo XXI Ciclo de conferencias «Tiempos de crisis», Madrid, 2012.

— «La gestión del Banco Central Europeo ante la crisis», Revista de Economía Mundial, 30, 2012.

— «La crisis financiera mundial: Lecciones y retos», en P. Martín-Aceña (ed.), Pasado y Presente: de la Gran Depresión del siglo XX a la Gran Recesión del siglo XXI, Fundación BBVA, Madrid.

GonzÁlez Velasco, M.C. y Brinckman, R.: «Análisis de la integración y dependencia de las políticas monetarias de la Unión Europea», Pecvnia Monográfico, 2011.

Gordillo Pérez, L.I. y CANedo, J.R., «La Constitución económica de la Unión Europea. Bases de un modelo en constante evolución», en Cuadernos de Derecho Transnacional (Marzo 2013), Vol. 5, № 1, pp. 163-183.

Gordillo PÉrez, L.I., «Constitución económica, ordoliberalismo y Unión Europea. Ensayo de una caracterización del Derecho económico europeo», en GARCÍA GUERRERO, J. L. (Dir.), Constitucionalizando la globalización, Tirant, Valencia, 2018, vol. I, pp. 813-845.

LiCHTESZTEJN TESZLER, S.: «Efectos observados y efectos inesperados de la crisis global», Iztapalapa, Revista de Ciencias Sociales y Humanidades, $\mathrm{n}^{\circ}$. 70, enerojunio, 2011.

Malo De Molina, J. L.: «La respuesta del Banco Central Europeo a la crisis», Boletín Económico del Banco de España, nº.115, julio-agosto, 2013.

Mangas Martin, A. y LiÑAn Nogueras, D.: Instituciones y Derecho de la UE, $6^{\mathrm{a}}$ edición, Tecnos, Madrid, 2010.

Mejia Garcia, L. y Rodriguez Nava, A.: «Estrategias de política monetaria en respuesta a la crisis global», Argumentos, Vol. 26, n. 71, Universidad Autónoma Metropolitana Unidad Xoclimilco, Distrito Federal, México, enero/abril 2013

Millaruelo, A. y Del Rio, A.: «Las medidas de política monetaria no convencionales del BCE a lo largo de la crisis», Boletín económico, Vol. enero de 2013.

NuÑEZ RAMOS, S.: «La respuesta a la crisis financiera internacional: medidas de estabilización financiera y estrategias de salida», Presupuesto y Gasto Público, 59, Instituto de Estudios Fiscales 2010.

O’KEAN, J.M". «La crisis financiera y la Unión Monetaria», en Unión Europea, armonización y coordinación fiscal tras el Tratado de Lisboa, Universidad Pablo Olavide, Sevilla, 2011

Parejo Alfonso, L.: Crisis y renovación en el Derecho Público, CEC, Madrid, 1991.

ReInHart, C. y. RogofF, K.S; «Growth in a time of debit», National Bureau of Economic Research; January 2010.

SAAVEDRA SERRANO, M.C.: «La integración financiera y el nuevo sistema de gobernanza de la Unión Económica y Monetaria», Revista Universitaria Europea $\mathrm{n}^{\circ}$ 26, Enero-Junio 2017, pp. 55-90. 
TRUCCO, P.: «¿Carga o privilegio? El dólar estadounidense y la puja por la reforma del sistema monetario internacional», Estudios Internacionales 169, Instituto de Estudios Internacionales, Universidad de Chile, 2011.

Vicenç NAVARRo: «¿Por qué la UE tiene un menor crecimiento económico que EEUU?», Temas para el debate, $n^{\circ} 125,2005$

«Si la Unión Europea tuviera un sistema federal como EEUU», Temas para el debate, $\mathrm{n}^{\circ} 197,2011$. 


\title{
EL TRANSITO DE LA CRISIS DE 2007 A UNA POLITICA FISCAL COMÚN EN LA UE: LOS EUROBONOS Y EL PAPEL DEL BCE
}

\author{
The transition from the crisis of 2007 to a common eu fiscal \\ policy: eurobones and the role of the ECB
}

\author{
Fernando Martinez-Maillo Toribio \\ Doctor en Derecho \\ UNED
}

http://dx.doi.org/10.18543/ed-69(1)-2021pp127-153

\section{Copyright}

Estudios de Deusto es una revista de acceso abierto, lo que significa que es de libre acceso en su integridad. Se permite su lectura, la búsqueda, descarga, distribución y reutilización legal en cualquier tipo de soporte sólo para fines no comerciales, sin la previa autorización del editor o el autor, siempre que la obra original sea debidamente citada y cualquier cambio en el original esté claramente indicado

Estudios de Deusto is an Open Access journal which means that it is free for full access, reading, search, download, distribution, and lawful reuse in any medium only for non-commercial purposes, without prior permission from the Publisher or the author; provided the original work is properly cited and any changes to the original are clearly indicated. 